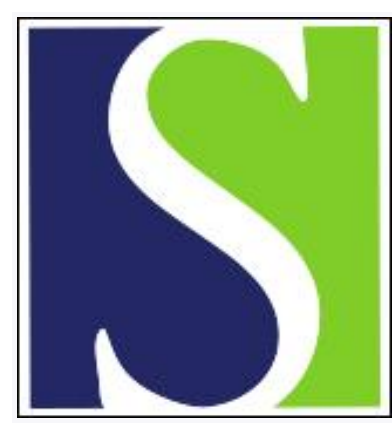

Scand J Work Environ Health 1990;16(1):51-54

https://doi.org/10.5271/sjweh.1821

Issue date: 1990

Physiological and psychological effects of exposure to extremely low-frequency electric and magnetic fields on humans.

by Gamberale F

Affiliation: National Institute of Occupational Health, Solna, Sweden.

This article in PubMed: www.ncbi.nlm.nih.gov/pubmed/2189221

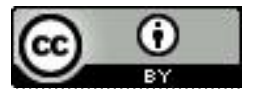




\title{
Physiological and psychological effects of exposure to extremely low-frequency electric and magnetic fields on humans
}

\author{
by Francesco Gamberale, $\mathrm{PhD}^{1}$
}

\begin{abstract}
GAMBERALE F. Physiological and psychological effects of exposure to extremely low-frequency electric and magnetic fields on humans. Scand J Work Environ Health 1990;16(suppl 1):51-4. Research into the hypothetical adverse effects on health that might result from living or working in the proximity of high-voltage power lines has been intense over the last decade. The present paper provides a brief review of the human studies concerned with the physiological and psychological effects of exposure to extremely low-frequency electric and magnetic fields. It was concluded that, on the basis of available experience, electric and magnetic fields associated with transmission lines do not cause physiological or psychological effects to be considered as health hazards.
\end{abstract}

Key terms: behavioral effect, electric fields, magnetic fields, human studies.

During the last decade there has been a marked increase in the extension and use of overhead, high-voltage transmission and distribution lines in many countries. At the same time, a great deal of speculation and serious research has occurred concerning possible health risks arising from exposure to the extremely lowfrequency (ELF) electric and magnetic fields associated with the power lines. As a consequence research into the biological effects of exposure to these fields is undergoing rapid development.

When located in an electromagnetic field, the human body causes perturbation of the fields. At the same time, the electric and magnetic fields induce electric current in the exposed body. Natural ELF electric and magnetic fields are very weak compared with those of man-made origin. The strongest electric fields are found in the proximity of existing energy generating systems and high-voltage transmission lines at 50 or $60 \mathrm{~Hz}$. The electric field in the immediate vicinity of a $400-\mathrm{kV}$ power line reaches about 2 million $\mathrm{V} / \mathrm{m},{ }^{2}$ but is reduced to only a few kilovolts per meter near the ground. The strength of the magnetic field near the ground under a $400-\mathrm{kV}$ power line is about $20 \mu \mathrm{T} .^{3}$

There is no doubt that exposure to electromagnetic fields can interfere with the natural electric fields in

\footnotetext{
I National Institute of Occupational Health, Solna, Sweden.

2 The strength of the electric field is measured in volts per meter $(\mathrm{V} / \mathrm{m})$.

3 The magnetic field is usually described in terms of its field strength, which is measured in amperes per meter, or in terms of its flux density, the strength of which is measured in tesla.
}

Reprint requests to: Professor F Gamberale, National Institute of Occupational Health, S-171 84 Solna, Sweden. the human or animal body and produce functional changes in the biological system. The following effects are fairly well documented. Both animals and humans may have a direct perception of the field. The field intensity threshold for this perception varies between 5 and $15 \mathrm{kV} / \mathrm{m}(1,2,3)$. The proximity of strong electric fields can cause the hairs on the human body to oscillate, and spark discharges may occur when a person insulated from the ground, eg, by rubber shoes, touches a grounded object or when a grounded person touches an insulated object (4). Exposure to magnetic fields can cause magnetophosphenes (5). This phenomenon is described as a sensation of flickering light induced in the eye. It occurs at field intensities greater than $10 \mathrm{mT}$ and at frequencies greater than $10 \mathrm{~Hz}$. The earth's natural magnetic field is known to affect the orientation of bees and birds (6). A pulsed magnetic field can have a therapeutic effect on bone growth and repair (7). ELF fields can interfere with implanted cardiac pacemakers (8).

During recent years two major reviews of the biological effects of ELF electric and magnetic fields have been published under the sponsorship of the World Health Organization $(1,9)$. These reviews address a broad spectrum of hypothesized effects associated with this type of exposure. Many of the biological effects reported, particularly those regarding experimental exposure of animals, are subtle and confounded by normal biological variation. The present paper has focused on human studies concerned with possible physiological and psychological effects of this exposure. For the question of whether exposure to electric or magnetic fields is associated with the incidence of cancer or affects fertility and reproduction, the reader is recommended to turn to one of the reviews that have already been mentioned. 


\section{Epidemiologic studies}

The first investigations of the health status of workers occupationally exposed to electric and magnetic fields were conducted in the Soviet Union in the early 1960s. Asanova \& Rakov (10) carried out a survey of workers in high-voltage switchyards exposed to electric fields up to $26 \mathrm{kV} / \mathrm{m}$. They reported that such exposure could cause functional disorders in the autonomic and central nervous system. These findings were subsequently confirmed in two other studies of switchyard workers in the Ukraine $(11,12)$. On the whole, about 500 workers were examined in these studies. The subjective complaints reported by the workers included fatigue, irritability, headache, loss of appetite, dizziness, nausea, sleep disturbances, reduced libido, and various manifestations of impaired functional capacity. Some physiological effects were also recorded objectively, eg, hematological changes, sinus arrhythmia, and sinus tachycardia by electrocardiography and desynchronized alpha activity and focal activations by electroencephalography. They also reported impaired performance in psychomotor and vigilance tasks. From the fact that the described symptoms were observed particularly among the most exposed workers evolved the idea of the existence of a threshold beyond which exposure should be avoided. Thus Fillipov (13), referring to experiments on exposed volunteers showing hematological changes, proposed a threshold of $5 \mathrm{kV} / \mathrm{m}$.

Indications of health effects similar to those observed in the investigations of the switchyard workers were also found by other researchers in the Soviet Union among workers exposed to static magnetic fields in the manufacture of permanent magnets $(14,15)$.

The results of these studies prompted similar investigations outside the Soviet Union. However, with the exception of a study on a small number of Spanish switchyard workers (16), comparable health surveys on occupationally exposed workers performed in the United States $(17,18)$, Canada $(19,20)$, Spain $(21)$, Sweden (22), the United Kingdom (23), and Italy (24), have failed to confirm the health effects reported in the Soviet Union. Furthermore, health effects associated with exposure to electric and magnetic fields could not be demonstrated either among farmers working in the proximity of a $765 \mathrm{kV}$ power line $(25,26)$ nor among people, both adults and children, living less than $25 \mathrm{~m}$ from a high-voltage power line (27).

It is evident that the epidemiologic results on the health effects of exposure to ELF electric and magnetic fields or exposure to static magnetic fields are highly contradictory. At this point it is natural to question why the symptoms observed in the earlier studies could not be validated in more recently performed investigations. Several hypotheses have been formulated to explain this discrepancy in the results. Danilin et al (28), eg, suggested that the results might have been produced by exposure to solvents, which is very com- mon in Soviet high-voltage substations. However, most of the symptoms reported in the earlier investigations were of a functional nature and may have been caused by many other agents in the work environment. For this reason the lack of reference groups in the earlier studies constitutes a severe limitation to the interpretability of the results in terms of causal relationships.

It has been suggested that exposure to magnetic fields might influence the occurrence of mental illness and suicide. Thus in the West Midlands Perry et al (29) found a relationship between the locations of suicidal deaths and the calculated electrical and magnetic fields from power lines. This study has been severely criticized on the grounds of incorrect use of epidemiologic data and major errors in the calculations of the magnitude of the electric fields.

\section{Experimental studies}

One of the advantages of the laboratory experiment compared with the epidemiologic study is that the former allows the investigator to manipulate the field exposure to create the conditions to be studied. The experimental approach also enables the investigator to avoid or control the influence of extraneous factors on the subjects. For these reasons the results of an experiment can be interpreted in terms of causal relationships.

In analogy to the concept of dose-response relationships of neurotoxic compounds, the effects of electric and magnetic fields may intensify with increasing exposure from a mild, acute effect confounded by the homeostatic mechanism to a severe, irreversible injury. The human experimental study on volunteers is appropriate to reveal and describe the effects in the lower part of the hypothesized dose-response function.

Some research workers have focused their attention on the capacity of the nervous system to perceive the presence of a magnetic field. Thus Denisov et al (30) and Kholodov \& Berlin (31) obtained a perception threshold at $3 \mathrm{mT}(10 \mathrm{~Hz})$ for pulsed magnetic fields. The latter investigators also found the threshold for sweeping magnetic fields to be $0.5 \mathrm{mT}$ and that for static fields to be $8 \mathrm{mT}$.

Most of the experimental studies on the effects of electric and magnetic fields on humans have been performed in the Federal Republic of Germany. Two types of effects have been studied, hematopoietic reactions and effects on the nervous system and behavior. In a series of experiments performed by Wever (32), exposure to weak electric and magnetic fields $(2.5 \mathrm{~V} / \mathrm{m}$, $10 \mathrm{~Hz}$ ) was found to shorten the circadian rhythm by more than $1 \mathrm{~h}$. It was also found that shielding subjects from natural magnetic fields prolonged the circadian rhythm by about $20 \mathrm{~min}$. In these experiments static electric and magnetic fields up to $600 \mathrm{~V} / \mathrm{m}$ did not cause any effect on circadian rhythm. On the basis of these results Wever postulated the existence of a physiological detector of weak electric fields. He did 
not consider these results to indicate the possibility of health effects.

In another series of experiments carried out over several years, Hauf (33) exposed more than 100 volunteers to fields ranging from 1 to $20 \mathrm{kV} / \mathrm{m}$ for periods of up to $5 \mathrm{~h}$. In these experiments no field-related effects were observed on psychomotor functions, heart rate, blood pressure, the electrocardiogram, or the electroencephalogram. The only effects reported were slight changes within the normal physiological range in some blood cell variables and a slight positive effect on fatigue in a psychomotor task. However, no changes in blood chemistry could be detected by Rupilius (34) in subjects who had been exposed for $3 \mathrm{~h}$ to $\mathrm{a} 20 \mathrm{kV} / \mathrm{m}$ electric field and a $0.3 \mathrm{mT}$ magnetic field at $50 \mathrm{~Hz}$. In a Swedish study (35) the same exposure intensity did not affect reaction time or the performance of other psychomotor and cognitive tasks. More recently, Sander et al (36) exposed volunteers for a week $(4 \mathrm{~h} / \mathrm{d})$ to electric $(20 \mathrm{kV} / \mathrm{m})$ and magnetic $(5 \mathrm{mT})$ fields and studied possible changes in blood pressure, body temperature, electrocardiograms, electroencephalograms, performance in psychomotor tasks, and hematologic and biochemical variables. None of these parameters was affected by the fields.

Experimental studies specifically addressing the question of the existence of acute effects of exposure to electric and magnetic fields have been performed more recently in the United States and the United Kingdom. Some field-related effects have emerged from these studies. In the American studies $(37,38)$ a double blind experimental model was used, and 12 subjects were exposed for $6 \mathrm{~h}$ to $9 \mathrm{kV} / \mathrm{m}$ and $19 \mu \mathrm{T}$ and to control conditions. During the exposure the subjects were examined with respect to several perceptual, psychomotor, and cognitive functions and also with respect to physiological and psychophysiological functions. Furthermore numerous hematologic, chemical, biochemical, and immunologic parameters were monitored during the exposure. The results showed that exposure had little effect on vital signs, field-related symptoms, performance, or daily life activities. There were, however, clear field-related changes in evoked potentials after both acoustic and optic stimulation and a field-related decrease in heart rate at rest. The latter effect was verified in a recently performed replication of the study. In the English studies $(39,40)$ the subjects were exposed to an electric field corresponding to $36 \mathrm{kV} / \mathrm{m}$. Exposure was found to bring about changes in mood and a performance decrement in a reasoning task.

To my knowledge only one study has been performed to evaluate the acute effects of exposure to electric and magnetic fields on occupationally exposed workers directly at the worksite (41). In this quasiexperimental study 26 linesmen were studied during two workdays while performing simulated routine inspection of insulators on steel poles of a $400 \mathrm{kV}$ power line. During one of the workdays the inspection was performed on a power line in operation, and the other day the same work procedure was performed on an identical power line, which was not, however, in operation. The mean exposure for the workday was $2.8 \mathrm{kV} / \mathrm{m}$ and $23.3 \mu \mathrm{T}$. The possible effects of exposure were studied with a battery of four automated performance tests, electroencephalography, a mood scale, and a questionnaire for the assessment of subjective symptoms. All the workers were examined immediately before and after each workday. Furthermore, blood samples were collected for each subject on three different occasions during each workday. They were used for an analysis of possible changes during the workday with regard to the following hormones: thyroid stimulating hormone, luteinizing hormone, follicle stimulating hormone, prolactin, cortisol, testosterone, and neopterine. There was no statistically significant difference between the two conditions which could be attributed to exposure to electric and magnetic fields. It should be mentioned that the same methods used in this study had previously been applied in field studies and had proved to be sensitive to the acute effects of low-dose exposure to organic solvents.

\section{Concluding remarks}

The general impression gained from the epidemiologic and experimental data is that neither electric nor magnetic fields of the strength encountered in the proximity of high-voltage power lines or substations constitute a health hazard for the general population or for the occupationally exposed worker. Naturally great caution must be used in drawing conclusions regarding the health risks from this type of exposure exclusively on the basis of the studies concerned with the physiological and behavioral effects. The question of whether exposure to electric and magnetic fields is associated with an increase in the incidence of cancer among children and adults and that of whether exposure is associated with increases in genetic defects or abnormal pregnancies are still to be answered.

\section{References}

1. World Health Organization. Magnetic fields. Geneva: World Health Organization, 1987. (Environmental health criteria 69.)

2. Cabanes J, Gary C. Direct perception of electric fields. In: International conference on large high voltage system. Stockholm, 1981. (CIGRE-paper 233-08.)

3. Deno DW, Zaffanella LE. Electrostatic effects of overhead transmission lines and stations. In: Transmission line reference book $345 \mathrm{kV}$ and above. Palo Alto, CA: Electric Power Research Institute, 1975:248-80. (EPRI report EL-100-1.)

4. Reilly JP, Larkin WT, Taylor RJ. Human reactions to transient electric current. Laurel, MD: The John Hopkins University, 1981-1982. (APL CPE 82:01, 82:02, vol I-IV.)

5. Lövsund P. Biological effects of alternating magnetic fileds with special reference to the visual system [Dissertation]. Linköping (Sweden): Linköping University, 
1980. (Dissertation no 47.)

6. Adey WR. Tissue interactions with nonionizing electromagnetic fields. Physiol Rev 1981;61:435-514.

7. Bassett CAL. Pulsing electromagnetic fields: a new method to modify cell behavior of calcified and noncalcified tissues. Calcif Tissue Int 1982;34:1-8.

8. Bridges JE, Frazier MJ. The effects of 60 Hertz electric and magnetic fields on implanted cardiac pacemakers. Palo Alto, CA: Electric Power Research Institute, 1979. (EPRI report EA 1174.)

9. World Health Organization. Extremely low frequency (ELF) fields. Geneva: World Health Organization, 1984. (Environmental health criteria 35.)

10. Asanova TP, Rakov AI. The state of health of persons working in electric fields of outdoor 400 and $500 \mathrm{kV}$ switch-yards [in Russian]. Gig Tr Prof Zabol 1966;10: $50-2$.

11. Revnova NV, Azaova TP, Semenovskaya NA. Effects of the high-intensity electric field of industrial frequency. In: Proceedings of the all-union symposium on the hygiene of labour and biological effects of the radiofrequency electromagnetic waves. 1968.

12. Sazanova TE. Physiological and hygienic assessment of labour conditions at $400-500 \mathrm{kV}$ outdoor switch-yards. Institute of Labour Protection of the All-Union Central of Trade Unions, 1967. (Scientific pubs issue 46, Profizdat). (Translation in special publication no 10, Piscataway, NJ: IEEE Power Engineering Society, 1975).

13. Fillipov V. Der Einfluss von electrischen Wechselfeldern auf den Menschen. In: Int Colloquium für die Verhtung von Arbeitsunfllen und Berufskrankheiten durch Elektrizitt. Köln: Berufsgenossenschaft der Feinmechanik und Elektrotechnik, 1972:170-7.

14. Abranıvich-Poljakov DK, Kleiner AI, Kolodub FA, et al. Clinical characteristics of effects of electromagnetic fields from contact welding. Vrach Delo 1979;4:106-19.

15. Vyalov AM, Shpil'berg PI, Yushkevish LB, et al. To the question of static and variable magnetic field effects on human organism. In: Scientific transactions. Moscow: FF Erisman Hygiene Research Institute, 1964: 169-75.

16. Fole FF, Dutrus E. Nueva aportacion al estudio de los campos electromagnéticos generados por muy altas tensiones. Med Segur Trab 1974;22:15-8.

17. Kouwenhoven WB, Langworthy OR, Singewald ML Knickerbocker GG. Medical evaluation of man working in AC electric fields. IEEE Trans Power Appar Syst 1967;86:506-11.

18. Singewald ML, Langworthy OR, Kouwenhoven WB. Medical follow-up study of high-voltage linemen working in AC electric fields. IEEE Trans Power Appar Syst 1973;92:1307-9.

19. Roberge PF. Study on the state of health of electrical maintenance workers on Hydro-Quebec $735 \mathrm{kV}$ power transmission system. Montreal: Institut de Recherche de l'Hydro, 1976. (Final report.)

20. Stopps GJ, Janischewsky W. Epidemiological study of workers maintaining HV equipment and transmission lines in Ontario. Vancouver: Canadian Electrical Association, 1979.

21. Malboysson E. Medical control of men working within electrical fields. Rev Gen Electr 1976; July(special number): $75-80$.

22. Knave B, Gamberale F, Bergström S, et al. Long-term exposure to electric fields: a cross-sectional epidemiologic investigation of occupationally exposed workers in high-voltage substations. Scand J Work Environ Health 1979;5:115-25.

23. Broadbent DE, Broadbent MHP, Male JC, Jones MRL Health of workers exposed to electric fields. $\mathrm{Br} \mathrm{J}$ Ind Med 1985;42:75.

24. Baroncelli P, Battisti S, Checcucci A, Grandolfo M, Serio A, Vecchia P. Uno studio trasversale sullo stato di salute di lavoratori esposti a campi elettromagnetici a $50 \mathrm{~Hz}$. Med Lav 1985;76:491.

25. Busby K, Driscoll PE, Washbon WE. A field survey of farmer experience with $765 \mathrm{kV}$ transmission lines. Albany, NY: State Campus, 1974. (Agricultural Resources Commission report.)

26. Dumansky YD, Popovich VM, Kozyarin IP. Effects of low frequency $(50 \mathrm{~Hz})$ electromagnetic field on functional state of the human body [in Russian]. Gig Sanit $1977 ; 12: 32-5$.

27. Strumza MV. Influence sur la santé humaine de la proximité des conducteurs de l'électricité a haute tension. Arch Mal Prof 1970;31:269-76.

28. Danilin VA, Voronin AK, Modorski VA. The state of health of personnel working in high-voltage electric fields in Russian. Gig Tr Prof Zabol 1969;13:51-2.

29. Perry FS, Reichmanis M, Marino AA, Becker RO. Environmental power frequency magnetic fields and suicide. Health Phys 1981;41:267-77.

30. Denisov VN, Gavrilov VA, Innonikov IN. Human reactions to the influence of electric and magnetic fields at industrial frequency. In: Living systems in electromagnetic fields. Tomsk (Soviet Union): University of Tomsk, 1979:54-64.

31. Kholodov YUA, Berlin YUV. Sensory reactions in man during interactions with magnetic fields. In: Electromagnetic fields in the biosphere: 11 . biological effects of electromagnetic fields. Moscow: Nauka, 1984:83-9.

32. Wever R. Influence of weak electromagnetic fields on the circadian periodicity of man. Naturwissenschaften 1968;55:29. (NASA translation, X68-182216.)

33. Hauf G. Untersuchungen über die Wirkung energietechnischer Felder auf den Menschen [Dissertation]. Freiburg am Breisgau (Federal Republic of Germany): J Krause, 1974.

34. Rupilius JP. Untersuchungen über die Wirkung eines electrischen und magnetischen $50 \mathrm{~Hz}$-Wechsel auf den Menschen. Freiburg: University of Freiburg, 1976.

35. Johansson R, Lundquist AG, Lundquist S, Scuka V. Is there a connection between the electricity in the atmosphere and the function of man? Part III: $50 \mathrm{~Hz}$ field variations. Stockholm: Swedish Defence Research Establishment, 1973. (FOA report C2621-45.)

36. Sander R, Brinkmann J, Kuhne B. Laboratory studies on animals and human beings exposed to $50 \mathrm{~Hz}$ electric and magnetic fields. In: International congress on large high-voltage electric systems. Paris: 1982. (CIGRE paper 36-01.)

37. Fotopoulos SS, Cook MR, Gerkovich MM, Koontz E, Graham C, Cohen HD. Effect of $60-\mathrm{Hz}$ fields on human biochemical activity. In: Contractors review meeting. St Louis, MO: Department of Energy, Electric Power Research Institute and New York State Power Lines Project, 1984.

38. Graham C, Cohen HD, Cook MR, Gerkovich MM, Phelps JW, Fotopoulos SS. Human exposure to $60-\mathrm{Hz}$ fields: effects on performance, physiology and subjective state. In: Contractors review meeting. St Louis, MO: Department of Energy, Electric Power Research Institute and New York State Power Lines Project, 1984.

39. Bonnell JA, Broadbent DE, Lee WR, Male JC, Norris WT, Stollery BT. Can induced $50 \mathrm{~Hz}$ body currents affect mental functions? In: Proceedings of the conference on electric and magnetic fields in medicine and biology. London: Institution of Electrical Engineers, 1985.

40. Stollery BT. Effects of $50 \mathrm{~Hz}$ electric currents on mood and verbal reasoning skills. Br J Ind Med 1986;43:339.

41. Gamberale F, Anshelm Olson B, Eneroth P, Lindh T, Wennberg A. Acute effects of ELF electromagnetic fields: a field study of linesmen working with $400 \mathrm{kV}$ power lines. $\mathrm{Br} \mathrm{J}$ Ind Med 1989;46:729-37. 